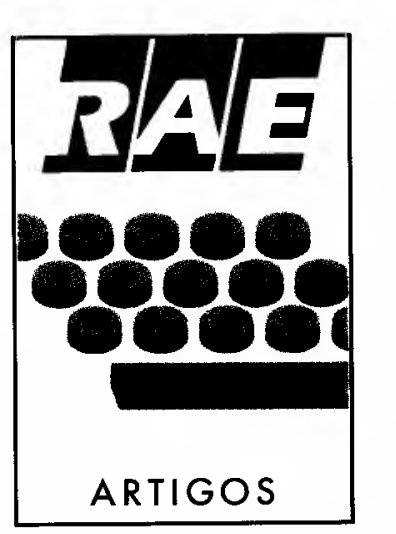

\title{
UM POUCO ALÉM DO JUST-IN-TIME: UMA ABORDAGEM À TEORIA DAS RESTRIÇÕES
}

O modo global de gerenciar a empresa através da Teoria das Restrições tem se mostrado superior ao do Just-in-Time.

The global way of managing the enterprise supported by the Theory of Constraints is showing superior than Just-in-Time.

\section{PALAVRAS-CHAVE:}

Restricões, gargalos, ganhos, lucro liquido, retorno sobre 0 investimento, contabilidade de custos, nova revolução gerencial.

\section{KEY WORDS:}

Constraints, bottlenecks, earnings, net profit, return on investment, cost accounting. new managerial revolution.

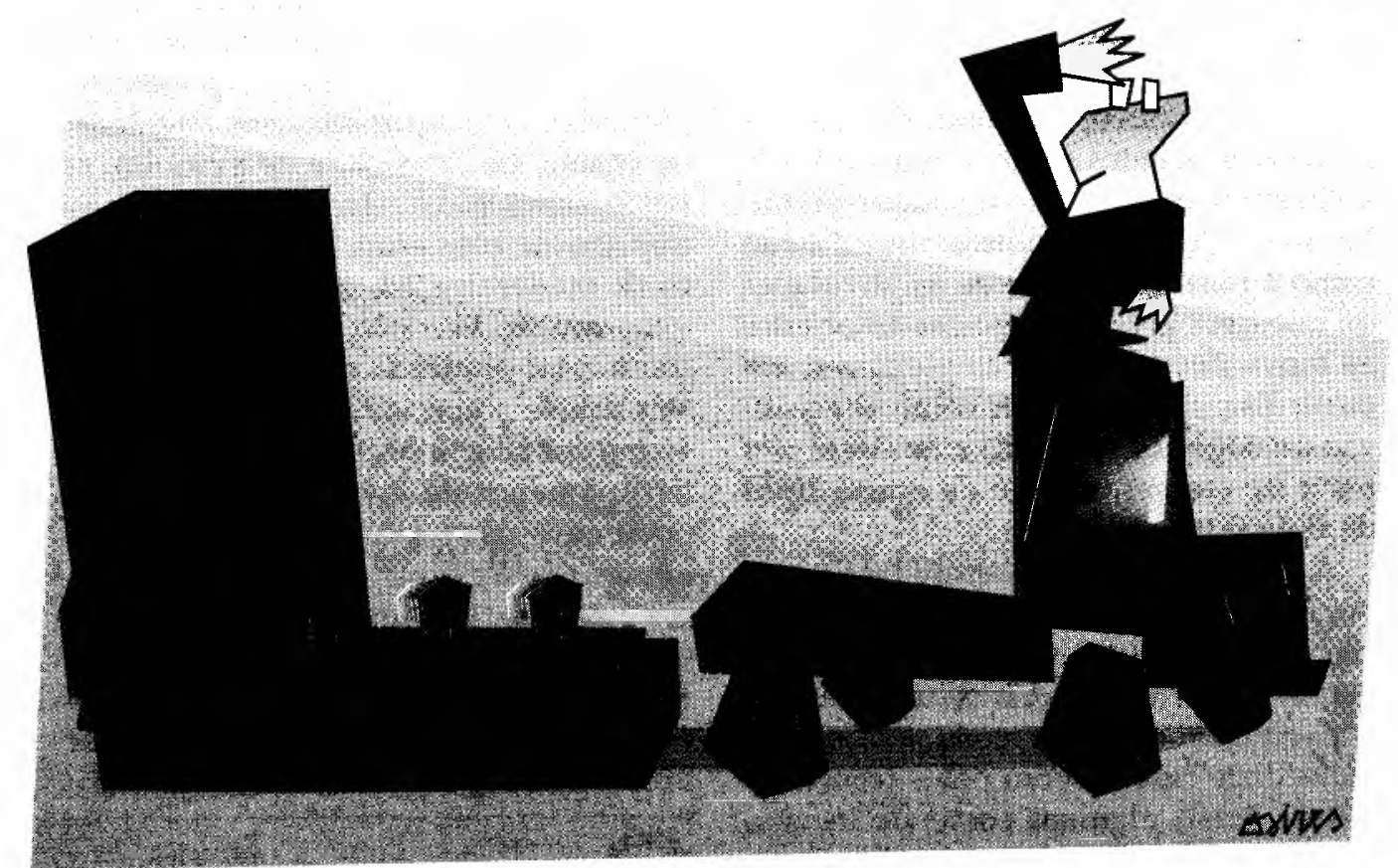


A filosofia gerencial Just-in-Time, surgida no Oriente, dominou a manufatura mundial nas décadas de 60,70 e 80 . A Teoria das Restrições surge como uma resposta do Ocidente aos crescentes avanços das indústrias instaladas no Sudeste Asiático. Países como Japão, Tailândia, Coréia do Sul, Taiwan e Cingapura são considerados Tigres Asiáticos por terem crescido a uma taxa média de $6 \%$ ao ano.

Devemos, antes de tudo, tecer considerações sobre as diferenças entre OPT Optimized Production Technology - e TOC. - Theory of Constraints. A primeira surge dentro do ambiente fabril, enquanto que a segunda tem um caráter macro, ou seja, procura verificar e estudar não somente as restrições das máquinas e equipamentos, mas também as restrições de mercado, políticas e econômicas.

A filosofia gerencial Just-in-Time procura a otimização da produção e do ambiente, considerando que todas as variáveis envolvidas possuem a mesma ponderação. A Teoria das Restriçōes procura tratar o ambiente envolvente de forma diferenciada e localizar os gargalos (bottlenecks) em se tratando da produção. Finanças, Marketing, Logística, assim como variáveis políticas e econômicas estão no âmbito de estudo da Teoria das Restrições. A Teoria das Restrições é automotivável, ao passo que a filosofia gerencial Just-in-Time năo o é, necessitando sempre de uma busca constante de motivação e do envolvimento dos empregados.

Os resultados apresentados säo mais rápidos do que os verificados na Teoria das

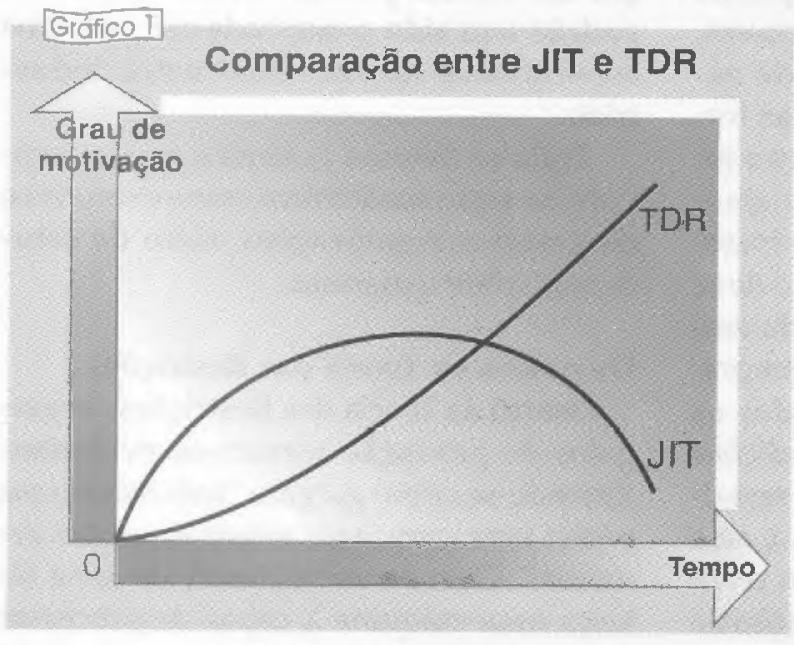

Restriçōes, porém, poderá haver uma desmotivação a partir de um certo intervalo de tempo " $t$ " (ver gráfico 1).

\section{DESENVOLVIMENTO}

Criada pelo israelense Eliyahu M. Goldratt, na década de 80 , baseada em programas de computação fundamentados na programação linear, podendo ser utilizada em qualquer tipo de ambiente, fabril, comercial ou de serviços ${ }^{1}$, a Teoria das Restrições mostra que a meta de qualquer organização é o aumento do throughput ou índice pelo qual o sistema gera dinheiro através de suas vendas líquidas ${ }^{2}$. Para Goldratt, o throughput pode ser definido como o "ganho", ou seja, a simples diferença aritmética entre o faturamento total e as matérias-primas consumidas. O ganho passa a ser uma medida operacional global, além de um conceito extremamente simplificado. Outro conceito é o do lucro líquido, entendido como a diferença entre o ganho e o somatório de todas as despesas operacionais. Finalmente, o retorno sobre o investimento passa a ser o quociente entre o lucro líquido e o inventário. Cabe aqui definirmos o throughput, que pode ser entendido como valor agregado ${ }^{3}$ ou o índice que indica a geração de dinheiro através das vendas. Já as despesas operacionais são todo o dinheiro que o sistema gasta para transformar inventário em valor agregado e por inventário entende-se todo o dinheiro que o sistema investe na compra de 'coisas' que pretende vender. Matematicamente, temos:
Throughput $=$ ganho $=$ faturamento - matéria-prima consumida; Lucro líquido $=$ ganho despesas operacionais;

Retorno sobre o investimento = lucro líquido/inventário.

\section{A META}

Segundo Eliyahu M. Goldratt ${ }^{4}$, a meta de qualquer organização industrial, comercial ou de serviços é "ganhar dinheiro no presente, bem como ga-
1. ANTUNES, J.A. V. J. et al Consideraçōes critic as sobre a evolução das filosofias de administraçāo da produçāo: do Just-in-Case ao Just-in-Time. Revista de Administraçāo de Empresas, v. 29, n. 3, p. 58, 1989 ,

2. GOLDRATT, E. M., COX, J. A meta. Introdução à edição brasileira revisada por Claudiney Fullman. São Paulo: IMAM, 1990.

3. Idem, ibidem.

4. Idem, ibidem. 
5. CSILLAG, Joāo M. Introdução à teoria das restriçōes. Palestra proferida em $6 / 11 / 90$, p. 7.

6. GOLDRATT, E. M., FOX, R. E. A corrida pela vantagem competitiva. São Paulo: IMAM, 1989 , p. 31.

7. IUDICIBUS, Sérgio de. Análise de balanços. 4. ed. São Paulo: Atlas, 1987, p. 24-42. rantir a sua continuidade no futuro." A maximização da satisfação no mercado mundial, o menor custo, a alta qualidade dos produtos fabricados e a maximização da riqueza dos acionistas são elementos decorrentes. As ações tomadas são o fruto de decisões de efeito-causa-efeito. Um problema núcleo que sempre existe imerso nesse processo propiciará uma preocupação com a cultura vigente, formando um conceito geral baseado na eqüidade dos recursos e dos produtos, sempre voltado à idéia de otimização, tanto local como geral. A partir daí, os resultados finais são conseqüência de resultados por produto, obtidos via sistemas que geram informações por produto. Os resultados finais são de difícil obtenção, dado que a participação e o engajamento das pessoas é diminuto, resultando em decisões não relacionadas aos objetivos finais e na tomada de decisões intuitivas, não-confiáveis 5 . Para que servem as ações? Para criar um elo através do qual seja possível atuar diretamente sobre o lucro líquido (medida absoluta), o retorno sobre inventário (medida relativa) - e sobre o fluxo de caixa da empresa (medida de sobrevivência) ${ }^{6}$.

\section{O ENFOQUE DA TEORIA DAS RESTRIÇÕES}

A Teoria das Restrições procura entrar no mundo do ganho em vez do mundo do custo. Este último é consagrado pelos princípios contábeis geralmente aceitos, dentre os quais destacam-se ${ }^{7}$ : princípio da entidade (onde as empresas são entidades distintas da pessoa dos sócios, quer sejam pessoas físicas ou jurídicas); princípio da continuidade (princípio do going/concern, onde é enfatizada a continuidade do negócio da empresa até que evidências fortes como liquidação judicial ou extra-judicial, persistência de prejuízos inviabilizem o negócio); princípio do custo histórico como base de valor (onde o ativo deve ser incorporado aos outros ativos da empresa pelo preço pago na data da compra. Além disso, devem ser incorporados os custos para colocar o ativo em condições de funcionamento. Aqui, devemos ressaltar que, num ambiente inflacionário, esse princípio passa a não mais refletir a realidade gerencial); princípio da realização da receita (reconhecido quando ocorre o lucro ou prejuízo real da transação industrial, comercial ou de serviços); princípio da competência de exercícios (quando receitas e despesas são reconhecidas única $\mathrm{e}$ exclusivamente em função dos seus respectivos "fatos geradores"); princípio do denominador comum monetário (princípio que obriga o estabelecimento de uma medida monetária-padrão para medição e aferição de resultados).

Quanto a esse último princípio, no Brasil, a unidade monetária comum de aferição de resultados é o real ( $R \$)$, observando-se as seguintes convenções: convenção da objetividade (princípio que visa a distinguir entre procedimentos relevantes $e$ irrelevantes e escolher sempre o mais objetivo); convenção do conservadorismo (onde deverá predominar a avaliação mais conservadora do ativo, do passivo e do patrimônio líquido das entidades. $O$ objetivo é: "Não antecipar receitas e apropriar todas as despesas e perdas possiveis"); convenção da materialidade (onde, para se evitar desperdícios de tempo e de dinheiro, registram-se somente os eventos dignos de atenção, pela sua materialidade, e no momento oportuno) e a convenção da consistência (onde os princípios contábeis não devem ser alterados periodicamente, de forma leviana, comprometendo o bom andamento na aplicação dos outros princípios).

Além desses princípios, existe o da alocação dos custos indiretos da fabricação que, geralmente, são apropriados em função dos custos diretos. A alocação em função do custeio por absorção ou custeiopadrão tem sido contestada até por altos especialistas na área dos custos industriais.

Trata-se de uma polêmica que tem envolvido tanto acadêmicos como executivos de grandes organizações, além de estudiosos sobre o assunto.

\section{Os passos na Teoria das Restrições}

Dentro da Teoria das Restrições, os gargalos de produção tornam-se evidentes. Entende-se como gargalo "todo recurso que possui uma capacidade menor que a sua demanda". Caso se tenha dentro de uma fábrica uma máquina $X$ capaz de processar 
apenas 600 toneladas de material por hora, e duas máquinas $Y$ e Z, subseqüentes ao processo de produção, que podem processar respectivamente 700 e 800 toneladas por hora, será impossível processarmos mais do que 600 toneladas por hora na máquina $X$. Trata-se, portanto, de uma restrição de capacidade, na qual se evidencia um gargalo.

O conceito apresentado é amplo. As restrições, como foram aqui posicionadas, podem estar localizadas no ambiente. Podemos ter restrições do mercado consumidor final quando este năo se dispuser a consumir os bens e serviços ofertados no mercado e restrição direta quando um produto ou um servico compete com o mesmo produto ou serviço da empresa (margarina A e margarina $\mathrm{B}$ da mesma empresa, por exemplo). A restrição do mercado é indireta quando a demanda do produto aumenta e, devido às restrições de capacidade, há uma redução na probabilidade do sistema em propiciar outro produto ou serviço equivalente.

Outra restrição própria do ambiente externo é a política. É a mais forte das restrições: muitos projetos são abandonados por falta de respaldo político. O correto entendimento dessas restrições torna-se vital para o desenvolvimento econômico do país, dada a imensa massa de recursos envolvida.

Há restriçöes geradas pelo fornecedor, quando fontes de suprimento são interrompidas, visando ao aumento de preços ou melhores vantagens de negociação com o comprador.

Portanto, o conceito de restrição fundamenta e viabiliza a Teoria das Restrições, um macroconceito, enquanto o conceito da Tecnologia de Produção Otimizada - TOP - liga-se estreitamente ao ambiente fabril.

Os passos na Teoria das Restrições são os seguintes: identificação das restrições - notadamente onde há um acúmulo de estoque; decisão de como explorar as restrições; subordinação dos elementos não restritos ao elemento restritivo; elevação do elemento restritivo; caso o elemento restritivo deixe de ser uma restrição, identifi- car a próxima restrição para repetir os passos anteriores. Cuidar, porém, para que a nova inércia não seja a próxima restrição.

\section{Mundo dos custos $x$ mundo dos "ganhos"}

Na percepção atual, em que predomina a visão do mundo do custo ${ }^{8}$, os gastos têm relação direta com o lucro líquido e com o retorno sobre o investimento. Os gastos constituem preocupação do primeiro escalão. As despesas operacionais tornamse, no mundo dos custos, um referencial conveniente para se atribuir valores às ações e aos seus impactos nos resultados finais. $\mathrm{O}$ investimento, ou mais precisamente o estoque disponivel, é relegado a um terceiro plano. No mundo do custo, as prioridades são: despesas operacionais, gastos gerais de fabricação e estoque.

Na percepção onde predomina o mundo do ganho, é definida a variável ganho, que está intimamente associada às vendas líquidas, dependente de clientes e fornecedores. Os benefícios do ganho são, de certa forma, intangíveis: qualidade do produto, prazo de desenvolvimento de novos produtos, desempenho das entregas, qualidade dos serviços prestados, automação industrial e retorno obtido sobre a propaganda.

Portanto, as prioridades no mundo do ganho tornam-se sem efeito, se comparadas com as do mundo dos custos: ganho ou vendas liquidas, inventário, despesas operacionais.

Cabe ressaltar que nesse ponto muitos erros são cometidos. A classe empresarial tem dificuldade em vislumbrar o mundo do ganho, onde predomina o bom senso
8. HOPP, J. C., LEITE, H. P. 0 crepúsculo do lucro contábil. Revista de Administração de $\mathrm{Em}$ presas, v. 28, п. 4, p. 55-63, 1988. 
9. Termo criado em homenagem ao "pai" da Teoria das Restrições como filosofia organizacional, Eliyahu M. Goldratt.

10. ANTUNES, J. A. V. J. et al Op. cit., p. 54-8.

11. GOLDRATT, E. M., FOX, R. E Op. cit., p. 100.

12. Idem, ibidem, p. 99. de vender produtos a um preço mais baixo com uma qualidade superior, procurando diminuir o inventário e, por último, cortando as despesas operacionais. A visão do mundo do custo recomenda, em caso de crise, o corte das despesas operacionais, o corte dos investimentos e, finalmente, a tentativa de manutenção da margem de lucro via aumento de preços, gerando estagflação.

\section{CARACTERÍSTICAS DAS FILOSOFIAS JUST-IN-CASE, JUST-IN-TIME E TEORIA DAS RESTRIÇÕES}

Buscando fornecer uma visão sumária, simples e objetiva dessas três filosofias gerenciais, é mister lembrar que elas são as pedras angulares do desenvolvimento da manufatura. Consubstanciaram-se como teorias e filosofias desde 1900 , quando o sistema de manufatura sofreu uma reorganização sem precedentes, através do taylorismo, do fayolismo, do fordismo, do ohnoísmo e do "goldrattismo".

\section{A maneira Ocidental - a filosofia Just-in-Case}

O enfoque convencional do Ocidente pode ser caracterizado como um sistema Just-in-Case. O ritmo de produção ditará quando as matérias-primas deverão ser li-

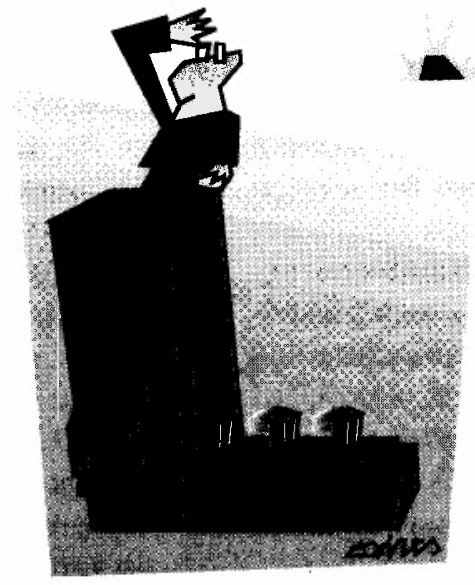

mercado. O sistema é de "puxar". A liberação de matéria-prima para a fábrica resulta de uma reação em cadeia iniciada pelo consumidor final. À medida que os produtos vão sendo vendidos, vão sendo fabricados. É o conceito de abastecimento e de reabastecimento do pulmão. "Pulmão" é entendido, nesse caso, como um “estoque de segurança”. É claro que o pulmão do sistema Just-in-Time é substancialmente menor do que o do Just-in-Case. Como a proteção ao estoque é menor, qualquer falta de material é vital para o processo de fabricação no sistema JIT. A linha de produção parará. Logo, as vendas atuais estão em perigo. Mas, dado que o estoque é menor, a capacidade de diversificar a linha de produtos é maior. Portanto, as vendas futuras aumentam, em função de um maior grau de competitividade no mercado. O sistema funciona como os elos de uma corrente. Diversificação da linha de produção implica flexibilidade.

A Teoria das Restrições

A Teoria das Restrições ${ }^{11}$ é baseada no fato de que existem Recursos com Restrições de Capacidade - RRC. A teoria reconhece que o RRC imporá o ritmo de produção para toda a fábrica. Haverá a necessidade de se criar um "estoque de seguberadas para a fábrica. Esse ritmo será determinado pela capacidade excessiva da primeira operação. Mesmo quando o operário não tem trabalho para fazer, possui matéria-prima para ser processada.

O resultado é um estoque consideravelmente mais alto do que no sistema Just-inTime. O valor agregado das vendas atuais está protegido. Porém, embora tenhamos um produto transformado, a nossa vantagem competitiva no mercado diminui drasticamente.

\section{A maneira Oriental - a filosofia Just-in-Time}

No enfoque Just-in-Time ${ }^{10}$, o ritmo da produção é determinado pela demanda do rança" para RRC. Procurando assegurar que o estoque não crescerá além do nível imposto pelo "estoque de segurança", deve-se limitar o índice pelo qual a matéria-prima é liberada para a produção.

Em outras palavras, o índice pelo qual será permitido que a operação inicial libere material para a produção será imposto pelo índice pelo qual o RRC estiver produzindo.

Na linguagem de Goldratt" ${ }^{12}$,"pulmão" é entendido como uma proteção para o recurso restritivo, "tambor" é a programação do recurso restritivo e "corda" é a ligação entre a primeira máquina e o recurso restritivo, garantindo a alimentação da primeira máquina no ritmo de processa- 
mento do recurso restritivo (ver figura 1).

Os dez mandamentos do dimensionamento da produção ${ }^{13}$ são os seguintes:

- a taxa de utilização dos recursos produtivos não vinculados ao gargalo (bottleneck) da produção não deve ser determinada pelo seus próprios potenciais de geração de trabalho, mas por alguma outra restrição ao sistema;

- ativar um recurso não é sinônimo de utilizá-lo eficazmente;

- uma hora perdida na operação do gargalo é uma hora perdida para o sistema como um todo;

- a economia de tempo em operações diferentes da operação gargalo é ilusória;

- os lotes de transferência podem não ser iguais aos lotes em processo e muitas vezes não o são;

- o tamanho dos lotes em processo deve ser variável e não fixo;

- as restrições de capacidade e demais prioridades devem ser consideradas simultaneamente e não seqüencialmente;

- os princípios de Murphy tornam-se menos incisivos, ou seja, seus "impactos" passam a ser mais facilmente administráveis;

- a capacidade da fábrica não deve ser balanceada;

- a soma dos ótimos locais não é igual ao ótimo global do sistema.

\section{Considerações acerca da Teoria das}

\section{Restrições}

A Teoria das Restrições surgiu como uma resposta do Ocidente aos contínuos avanços dos japoneses e dos Tigres Asiáticos. Procura tratar como importantes apenas os pontos do gargalo e não todos os pontos dentro de qualquer sistema.

A Teoria das Restrições coloca uma roupagem nova em conceitos antes consagrados. A passagem do mundo do custo para o mundo do ganho é extraordinária. Além disso, ajuda as empresas ocidentais a di- minuírem o gap tecnológico em relação às empresas orientais. É uma curva $\mathrm{ABC}$ do tipo 1-99. Isto é extremamente revolucionário. A teoria é robusta. Forte. Motivadora. Pungente. Permite modificações estruturais nas economias ocidentais. Merece, portanto, a atenção de estudiosos e de encarregados da prática da gestão empresarial.

\section{CONTRASTES E COMPARACÕES ENTRE AS FILOSOFIAS JUST-IN-TIME E A TEORIA DAS RESTRIÇÕES}

Num brilhante artigo publicado no periódico Production and Inventory Management, em 1986, Geerhard Plenert ${ }^{14}$, que completou sua tese de doutoramento pela Colorado School of Mines, e Thomas D. Best, Ph.D. e professor de Production and Operation Management na California State University, procuram debater a questão sobre qual seria a melhor técnica MRP Material Requirement Planning, ou seja, Planejamento das Necessidades de Material: JIT ou OPT? A pesquisa realizada pelo autor circunscreveu-se aos dois últimos itens e deve-se lembrar que este artigo cuida apenas do JIT e TOC.

\section{Diferenças entre países - fatores específicos}

É interessante começar a análise observando três realidades diferentes: Estados Unidos, Israel e Japão. Nos Estados Unidos, a terra não é um fator restritivo e as fábricas podem instalar-se em qualquer
13. ANTUNES, J. A. V. J. et al. Op. cit., p. 59-60.

14. PLENERT, G., BEST, T. D. MRP, JIT and OPT: what's the best? Production and Inventory Management Journal, p. 22-3, second quarter, 1986. 


\section{Comparaçāo entre JIT e TOC}

\begin{tabular}{|c|c|c|}
\hline & JIT & TOC \\
\hline \multirow{2}{*}{$\begin{array}{l}\text { Capacidade de } \\
\text { produçãa }\end{array}$} & - limitada & - limitada \\
\hline & $\begin{array}{l}\text { - controle através } \\
\text { do kanban }\end{array}$ & $\begin{array}{l}\text { - controle através } \\
\text { do gargalo ou } \\
\text { da restriçãa }\end{array}$ \\
\hline $\begin{array}{l}\text { Tamanhos dos } \\
\text { lotes }\end{array}$ & $\begin{array}{l}- \text { niveis multo } \\
\text { baixos }\end{array}$ & - variáveis \\
\hline \multirow[t]{3}{*}{$\begin{array}{l}\text { Sincronização da } \\
\text { produçāo }\end{array}$} & $\begin{array}{l}\text { - seqüência da produção } \\
\text { deve ser totalmente } \\
\text { sincronizada }\end{array}$ & $\begin{array}{l}\text { - Flutuações } \\
\text { decorrentes do uso } \\
\text { da capacidade } \\
\text { disponivel e de um } \\
\text { planejamento da } \\
\text { produçāo mais } \\
\text { rígido }\end{array}$ \\
\hline & $\begin{array}{l}\text { - uso do Kanban } \\
\text { para gerenciar flutuaçōes }\end{array}$ & $\begin{array}{l}\text { - ênfase no fluxo } \\
\text { contínuo do } \\
\text { processo } \\
\text { produtivo }\end{array}$ \\
\hline & $\begin{array}{l}\text { - busca do nivelamento da } \\
\text { produçä̃o }\end{array}$ & \\
\hline Acurácia & & $\begin{array}{l}\text { - vital nas áreas } \\
\text { com restrição } \\
\text { de capacidade }\end{array}$ \\
\hline Planejamento & $\begin{array}{l}\text { - menos completo } \\
\text { - menor velocidade } \\
\text { de respostas }\end{array}$ & $\begin{array}{l}\text { - mais completo } \\
\text { - maior velocidade } \\
\text { de respostas }\end{array}$ \\
\hline \multirow[t]{2}{*}{ Flexibilidade } & $\begin{array}{l}\text { - menos flexivel } \\
\text { - utilização de mais } \\
\text { estoque }\end{array}$ & $\begin{array}{l}\text { - mais flexivel } \\
\text { - utilização de } \\
\text { menos estoque }\end{array}$ \\
\hline & & $\begin{array}{l}\text { - melhor proteção } \\
\text { do RRC }\end{array}$ \\
\hline Custo & & $\begin{array}{l}\text { - dispensa o uso } \\
\text { de computadores }\end{array}$ \\
\hline
\end{tabular}

15. Team productivity está sendo utilizado para designar a produtividade oriunda de grupos de trabalho coesos. te, difícil a modificação dos produtos acabados. Em Israel, há um entrelaçamento desses dois pontos, permitindo uma flexibilidade apenas regular de produtos oferecidos ao mercado consumidor. Tratamse de três realidades distintas.

Em função dessas diferenças estruturais, as fábricas em território norte-americano e brasileiro tendem a scr cnormes, com desperdício de espaço onde são armazenados os produtos para atender a diferentes gostos.

Tanto a indústria norte-americana como a brasileira têm cnfatizado a produtividade individual do empregado, em contraste com a fisolofia reinante no Japão $\mathrm{c} \mathrm{cm}$ Israel do team productivily ${ }^{15}$. A diferença é claramente notada nos métodos de apuração de custos; tanto nos Estados Unidos como no Brasil, o enfoque é dado ao número de peças-padrão produzidas pelo empregado. Isto orienta o operador ou o cmpregado a um processo de produção onde talvez nem os produtos sejam necessários. A qualidade é colocada num segundo plano.

'lanto no sistema de produção japonês como no israelense, a qualidade do produto torna-se responsabilidade do empregado. O empregado não é avaliado pela quantidade produzida, mas pela produção executada sem desperdício. O sistema de produção é dependente da demanda do mercado. É o sistema de "puxar", pull.

No ambiente japonês de produção, os materiais alimentam a linha de produção à medida que os produtos finais são requeridos pelo mercado consumidor. Trata-se de um sistema de "elos" de uma corrente. A quebra de um dos elos resulta na parada da linha de produção. No Japão, o lead time de fabricação de uma motocicleta é de um ou dois dias, enquanto nos Estados Unidos é de um a dois meses. A diferença é visível: como nos Estados Unidos e no Brasil a programação dos departamentos de produção está sujeita à previsão de vendas, geralmente grandes quantidades de produtos não vendidos são acumulados em estoques, para satisfazer necessidades previstas.

No TOC, a produção ou os elementos a ele correlacionados não se baseiam num 


\section{VANTAGENS E DESVANTAGENS DO TOC (OPT)}

\section{Vantagens:}

1 - uma técnica simplificada para planejamento da produçăo onde: - os planejamentos não exigem muito tempa de preparaçāo.

- os planejamentos nāo necessitam de grande massa de dados:

- os dados nāo necessitam de grande acurácia;

- são necessárias poucas pessoas para analisarem 0 planejamento da produçãa;

2 - um processamento interativo complexo onde não ê necessário conhecimento prévia;

3 - uma rẩida projeçāo ou modificaçāo do planejamento onde: - no processo de manufatura, existe maximização de saidas (outputs) da produçāo e a minimização simultânea do estoque de produtos em processo ocorre através de técnicas, tendo como bases interaçôes matemáticas;

- é possivel um aumento de cerca de $10 \%$ ná taxa de produção, utilizando os mesmos recursos disponiveis:

- é possivel uma reduçāa de $20 \%$ no estogue de produtos em processo;

- o tamanho dos pequenos lotes são calculados com base na lucrativicade e não atravếs do lote econômico de compras e de produçãa);

- é permitido um controle mais preciso dos recursos a curto prazo; - levam-se em conta os recursos finitos existentes;

- năa há espaço para quaisquer tipos de erros

4 - é mais complexo dio que o JIT:

- planejamento rápido, modificação extremamente rápida

implica necessidade de maior flexibilidade;

- modíficaçöes no planejamento devem ser feitas em horas em vez de dias;

- dado que o planejamento seja de forma exiremamente rápida deve ser possivel executar diversas simulaçōes;

5 - permite análise acurada da planta industrial

- as restriçáes no processo de produçāo passam a ser claramente definidas;

- os melhoramentos podern ser feitos facilmente na planta industrial, graças à definiçăa clara das restriçōes; - através do processo de simulaçăo, dlversos mixes (camblnaçoes) de produtos podem ser experimentados com implicações para a planta industrial sob o ponto de vista de capacidade das máquinas e financeiro.

Desvantagens:

1 - necessidade de reorganização da planta industrial. Trata-se de uma reorganização conceitual dentro da planta industrial e dentro da empresa, embora seja menor do que a pieiteada pela filosofia JIT:

- modificaçăo do estilo gerencial para a conduçăo dos problemas;

- criaçăo de uma nova cultura;

- finalmente, movimentaçốes e modificaçōes de equipamento para que se possa aplicar a teoria mais eficientemente;

2

- ruptura dos sistemas tradicionais de contabilidade e de custos:

- a efíciênncia nãa pode mais ser calculada nesses sistemas;

- deixa-se de emitir as avaliaçōes de desempenho.

3 - ruptura no conceito dos usuários:

- os usuários dos sistemas devem ser retreinados; novos tipos de relatório devem ser desenvolvidos para dar suporte ao novo tipo de processamento de dados e os sistemas de contabilidade devem ser adaptados à nova base de informaçős. sistema de "puxar" ou de "empurrar", mas sim num sistema que focaliza os "gargalos" ou "restrições", sejam fabris ou pertinentes ao macroambiente estrutural. A produção é planejada em função do gargalo ou da restrição de capacidade. Como a fábrica inteira está subordinada à restrição, sua utilização a níveis máximos de uso otimizará, num certo patamar de produção, o restante da fábrica.

\section{CONCLUSÃO}

Os experts sentiram a necessidade de uma mudança nos métodos de manufatura como forma de enfrentar a concorrência internacional. Essa necessidade é concretizada, de certa forma, com a utilização das filosofias JIT ou TOC. Constatamos que, embora ambas as filosofias sejam altamente produtivas, o TOC é mais abrangente, mais localizado e inclui ainda todos os principios do JIT nesses pontos localizados. Em outras palavras, o TOC dá importância para aquilo que é importante e o JIT dá igual importância a tudo. Assim o TOC traz como conseqüência menor inventário total e maior proteção contra as paradas da linha de produção. A aplicação de um sistema é tão simples como o outro.

É uma filosofia que deve ser difundida para outros ramos, como comércio e serviços. Esse é um desafio para novas pesquisas a serem utilizadas neste campo profícuo e promissor: a ciência da Administração. $\square$

\section{4}

